AC 2008-836: A MODEL FOR DEVELOPING A SUSTAINABLE HOSPITAL IN TANZANIA

Greg Mowry, University of St. Thomas-St. Paul 


\title{
A Model for Developing a Sustainable Hospital in Tanzania
}

\begin{abstract}
Modern healthcare is expensive. In addition, hospitals are expensive to build and costly to maintain and sustain. In many developing countries the cost of modern healthcare services is prohibitively expensive and typically beyond the financial means of those who could directly benefit from such services. Furthermore, the diagnostics and instruments used in hospitals require a significant amount of electrical power along with the associated maintenance. Unfortunately reliable sources of electrical power are typically unavailable in developing countries. Consequently there are several significant obstacles, such as funding and power, which must be addressed in order to build and sustain a modern hospital in a developing country.

A business model was developed which is expected to provide the means and the necessary capital for powering and sustaining a modern hospital in some of the developing countries beyond their initial launch phase, which is typically supported through philanthropy and general humanitarian aid. The pilot hospital project, which is proceeding with the approval of the Tanzanian government, is part of the Dodoma Christian Medical Center (DCMC; see www.dthd.org) and is located near Dodoma, Tanzania.

In this paper the characteristics and necessary boundary conditions for success of the business model will be briefly described. Specific attention will be given to the evaluation process and selection of the alternative-energy based power systems that are needed for sustaining the hospital, the student service-learning work performed in support of this project, the engineering challenges, and the requirements for achieving long-term independent sustainability. The preliminary results to date indicate that with the proper set of conditions, modern healthcare can be introduced and sustained in developing countries.
\end{abstract}

\section{Introduction}

The hospital project is a planned addition to the DCMC and part of the Dodoma Tanzania Health Development (DTHD). Additional information regarding this development can be found at the DTHD web site. ${ }^{1}$ Active planning for the hospital began in late 2005. The projected cost and timeline of the hospital is approximately 3 million dollars over a period of 5 years respectively. The majority of this cost is associated with the building materials and power systems. Labor costs are typically not excessive in Tanzania. To minimize expenditures, the goal is to outfit the DCMC hospital with relatively new equipment obtained from equipment upgrades as they occur at sister hospitals. The Dodoma location of the DCMC hospital is somewhat remote from the main hydro-power generation locations (northern Tanzania) and existing transmission lines in 
Tanzania. Consequently the quality of the electrical power at the site is poor. As part of the longterm objective of maintaining and sustaining the hospital, the DCMC Board of Trustees also challenged the development team with the goal of powering the hospital with green and sustainable alternative-energy sources. The 'sustainable green-power-goals' and the 'low cost' of the hospital, combined with the 5-year timeline, made this project very unattractive to commercial developers. Typical projects of this dollar size, utilizing traditional power systems, are often completed in the United States in less than 12 months. In order to proceed with the project, the DTHD board contacted the School of Engineering at the University of St. Thomas (UST) to see if they would be interested in investigating, designing and ultimately implementing the power systems for the hospital. UST was approached because of their history of international outreach and involvement. ${ }^{2}$ The project was immediately embraced by UST. Furthermore, the DTHD board also agreed to financially support student researchers on an hourly basis and embrace the service-learning potential of the project.

There are many challenges that must be dealt with when implementing a project such as this in a developing country. Factors such as the culture, government, civil infrastructure and the economy must all be considered. Fortunately, Tanzanian cultural and governmental factors, while significant, actually play an important and immensely beneficial role in this project. However, the power-grid and lack of a transportation and heavy construction-machinery infrastructure represent significant challenges in Tanzania. Since a correlation has been shown to exist between 'human well-being' and the consumption (and availability) of energy and electricity $^{3}$, the lack of an adequate power grid in Tanzania directly impacts the ability to implement a modern hospital there. Furthermore, if a country does not continue to develop, the alternatives typically include poverty, disease and strife. The 'Human Development Index' or HDI, which is tracked by the United Nations, is a number representing the general economic and well-being of each country. The Human Development Index (HDI): "The HDI is based on three indicators: longevity, as measured by life expectancy at birth; educational attainment, as measured by a combination of adult literacy (two-thirds weight) and the combined gross primary, secondary and tertiary enrolment ratio (one-third weight); and standard of living, as measured by real GDP per capita." 3 The HDI as a function of electricity usage for 60 countries is shown in Figure 1. 


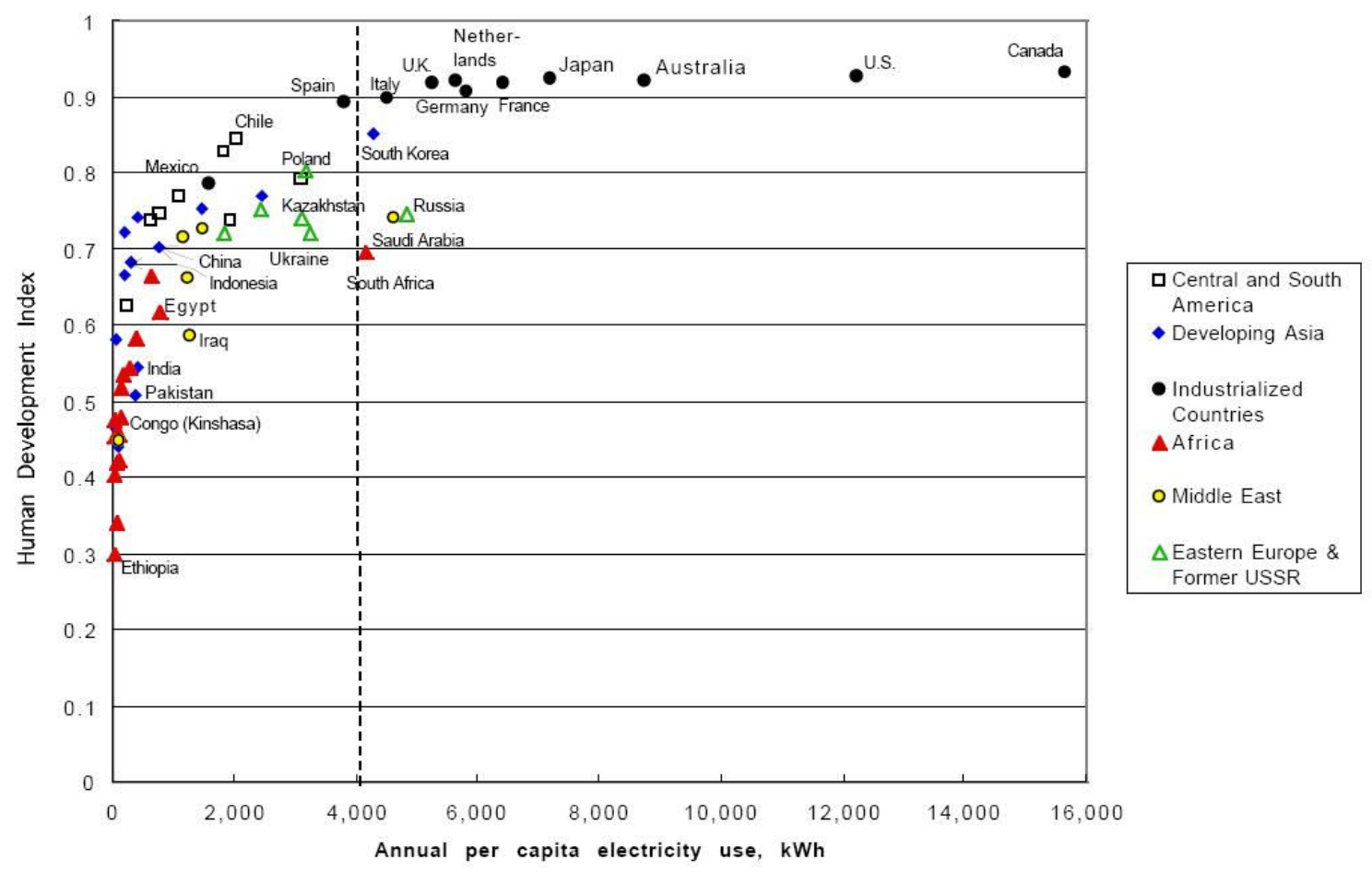

Figure 1. The United Nations' Human Development Index and electricity use. 60 Countries, 1997. Sources: Human Development Report 1999, United Nations Development Programme, Table 1; International Net Electricity Consumption Information, Energy Information Administration, U.S. Department of Energy, $<$ http://www.eia.doe.gov/pub/international/iealf/table62.xls>; International Data Base, U.S. Bureau of the Census, <http://www.census.gov/ipc/www/idprint.html>.

Africa has a significantly lower HDI that any of the developed countries. The dashed vertical line in figure 1 , at $4,000 \mathrm{kWh}$ per capita per year, represents the knee of the graph. Most industrialized countries, with an HDI $>0.9$, lie at or above this normalized power consumption level. Hence a hospital powered by a sustainable alternative-energy system could significantly and positively impact the surrounding regions in a country with a low HDI. Furthermore, if an energy surplus could be realized (i.e. supplying more energy than the hospital needs) then the surplus could be used in several additional ways to positively impact the local economy.

There is a long history of foreign aid to Africa. Many well-known governmental organizations (e.g. USAID ${ }^{4}$ ) along with the United Nations have given billions in aid to Africa. However corruption, greed, vested interests and selfishness have often resulted in fiascos with no longlasting positive affects. ${ }^{4,3}$ Many excellent charitable and non-government organizations (e.g. 'Christian Charity Fund' 6, 7 , 'Engineers Without Borders - USA' 8 and so forth) also support many projects in Africa (and elsewhere). However, there are two common themes in many of these efforts that often lessen the long-term beneficial impact of the projects. The first is that the efforts are not self-sustainable. That is, if (and often 'when') support from the parent organization ends then shortly thereafter so does the long-term viability of the project. The second theme is that of 'maintenance'. Almost every project or system, independent of its nature, must be maintained. Maintenance typical requires semi and/or skilled labor (with subsequent 
education and training requirements) as well as funds for replacing consumables and failed subsystems. Without maintenance, the long-term viability of all projects are limited at best. Several organizations, such as the 'Dodoma Tanzania Health Development' ${ }^{1}$ and the 'Peace House Foundation' 9 are attempting to address the sustainability and maintenance issues by integrating education, the development of trade-skills, and entrepreneurialism into their projects so that after an initial development period, projects are capable of being maintained and sustained by the recipient groups. Excluding emergency situations such as disaster relief, maintainability and sustainability are absolutely essential aspects for substantive long-term project impact.

The mission of the DTHD ${ }^{1}$ is " ... providing sustainable quality health care ... [to] central Tanzania." The key focus of this mission statement is the emphasis on 'sustainable'. In order to sustain healthcare in the Dodoma region of Tanzania, a continual income must be realized. The details of the business model for achieving this will be discussed later. Currently, the DCMC includes a dental clinic and a reproductive child health care center. The hospital is projected to become operational by 2010. As previously noted, an important part of this project is the encouragement of the Tanzanian governmental. As a public demonstration of their approval for this project, the President of Tanzania, Jakaya M. Kikwete, officiated at the laying of the foundation stone ${ }^{10}$ on June 29,2006 which marked the completion of the first phase of the DCMC. The Tanzanian government has continued to morally support the DCMC development.

\section{Business Model}

The primary objective of the business model is to obtain a self-sustaining hospital within some reasonable time frame. For the DCMC hospital, the goal is to achieve self-sustainability within 10 years of the completion date. As previously noted, self-sustainability ultimately requires sustainable sources of income. This requirement has several implications. First of all, local interest and ownership for the project must be cultivated. Local interest and support is absolutely essential for many reasons. For example, the locals are familiar with the proper channels for accomplishing tasks within their culture. They are instrumental in finding and procuring supplies, equipment, managing costs, and guiding the selection of those who are honest and truly motivated to help their people. Often village business and church leaders, when carefully screened for integrity, are instrumental in this task. Sources of income must be identified and carefully assessed. Examples of potential sources of income include energy production, food and water production, manufacturing basic building materials, education centers, and entrepreneurial parks. By providing jobs and the opportunity for entrepreneurialism the local economy can also be stimulated. An example of how entrepreneurialism can be fostered is by providing a safe location for development with reliable power. In this context, power and space for a small windturbine entrepreneur, such as Mr. Clive Johnson ${ }^{11}$, represents an excellent example of how a beneficial idea and project could be nurtured. For the DCMC, in order to foster regional support, it is necessary to ultimately retain and/or train Tanzanian doctors, nurses, business leaders and technicians. It is also important to the DCMC, that while the medical needs of the poor need to be addressed, the spirit and practice of ownership for one's future must also be cultivated. Longterm charity does not change the boundary conditions that trap the poverty stricken. This trap can only be broken by providing opportunities for education and jobs. Wherever possible, medical 
service fees should also be scaled to the financial means of the recipients so that a 'long-term charity' consumer mentality is not fostered. The magnitude of an undertaking such as this is clearly immense.

A flow diagram illustrating the revenue evolution as a function of time based on the business model is illustrated in figure 2 .

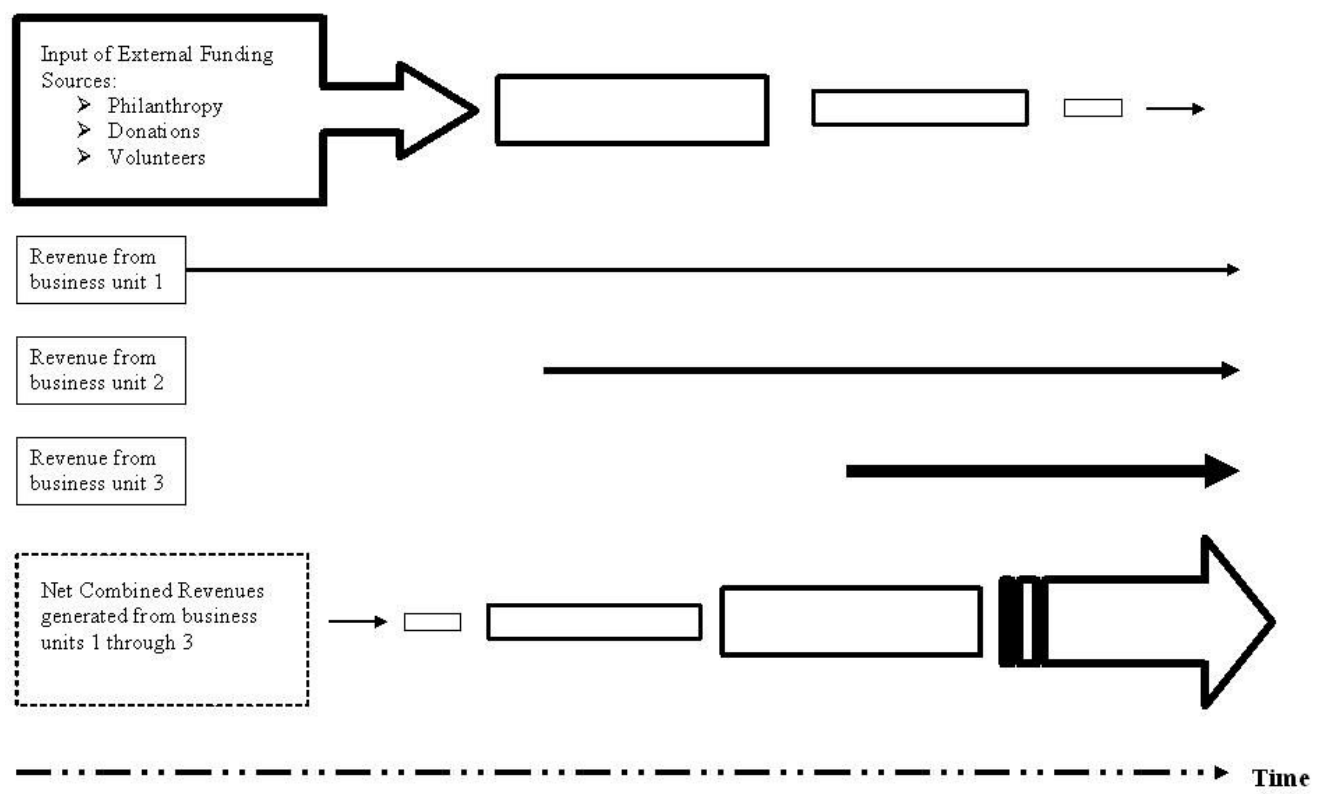

Figure 2. Revenue flow as a function of time for a self-sustaining project.

Over time, the various business units progressively increase their financial income and progressively supplant the need for external funding sources. The total project becomes selfsustaining when the net-income from the various business units meets their own respective needs and supplies the operating-and-maintenance cost-structure of the main project. Overall this implies that the various business units must make a profit. It is also important to match the production of the business units with the needs of the region and with the talent pool of the local population. This helps stimulate and improve the local economy. Success is correlated with how well the business-units match their raw materials-and-resource needs to locally available resources and their produced goods in relation to the immediate needs of that region. Education and training are implemented or supported as a means of improving the skill sets of the local population and providing opportunities for entrepreneurs.

The interrelation of revenues and electrical power between the various units comprising the overall DCMC, based on the business model, are illustrated in figure 3. Black arrows indicate cash flow while red arrows represent the flow of electrical power. The dashed red line represents the event where TANESCO ${ }^{12}$ (Tanzanian Electrical Supply Company) goes dark. In this event the power generation systems directly supply electrical power to the DCMC. 


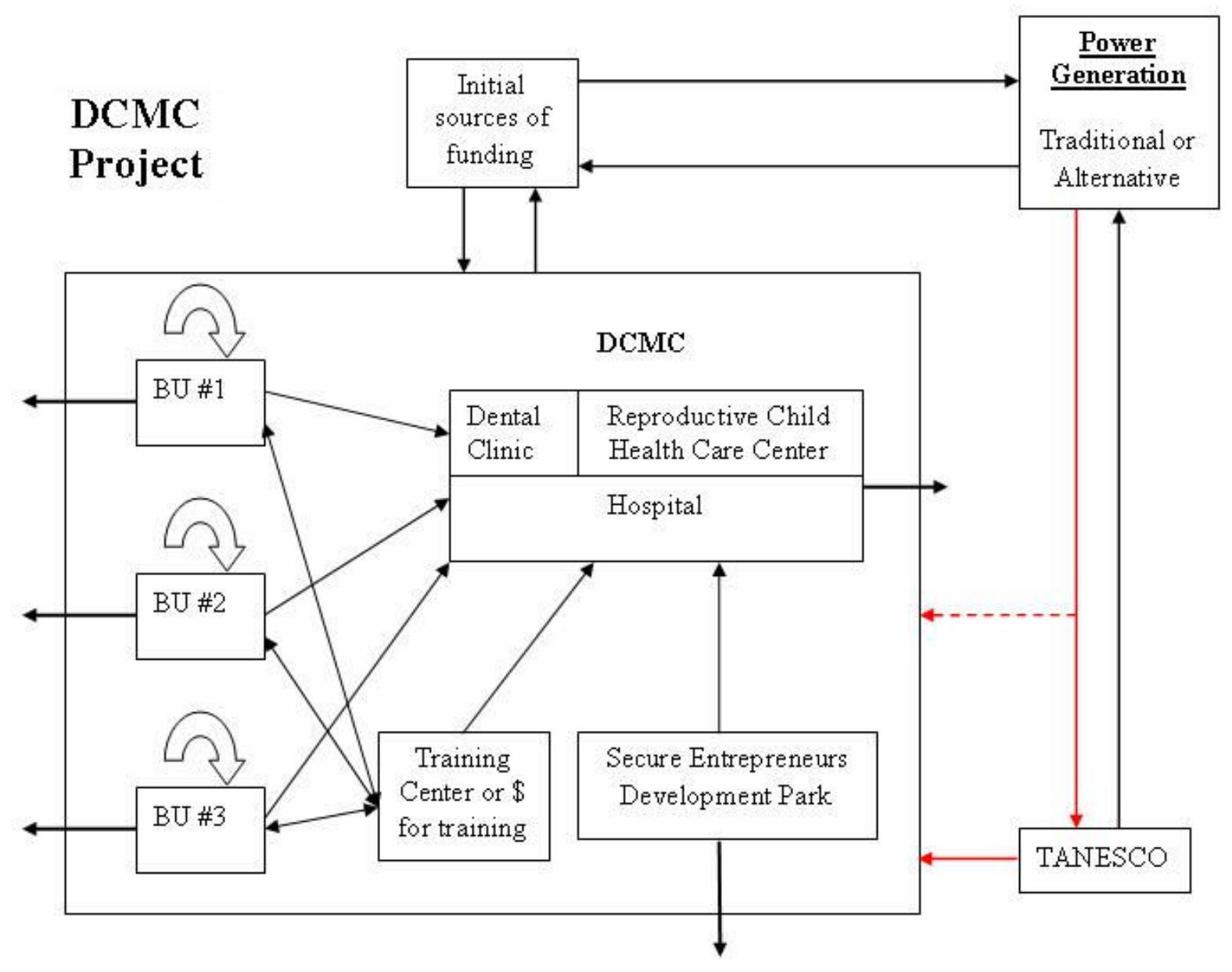

Figure 3. Revenue and power flow between the units comprising the DCMC

The overall project is initially launched with external funding. This is illustrated by the small central box at the top of the figure. Arrows indicate the flow of funds and/or resources between and within the units comprising the DCMC. The preliminary funding is used to launch the DCMC project as well as establishing a means of generating electrical power. Initially funding flows from the original donor sources to the overall project and the power systems. Over time the various business units (BU in Figure 3), the DCMC and the power systems provide enough funds to sustain the project. Ideally the project is even capable of generating enough funds to pay back the original investors who in turn are then free to use their resources to launch additional projects. The arrows exiting the DCMC project box indicate goods and services that flow to the surrounding community. The hope (or goal) is to sell power directly to TANESCO. Power can also be redirected into the DCMC project in the event that TANESCO cannot provide project power. A training center exists for preparing technicians to sustain and maintain the overall project. A safe and secure development park provides the necessary space and power for local entrepreneurs to develop their own businesses.

\section{The Hospital}


The fortune of simultaneously having the opportunity to provide both modern healthcare and power in a developing country is exciting. As previously noted, such an endeavor has the chance of affecting the 'local' HDI of a country in a substantive manner. The proposed size of the DCMC hospital will accommodate 80 patient beds along with the associated labs, care units, operating rooms and support functions. Due to the equatorial location of the site and the local civil engineering infrastructure, the hospital will be a single-story-structure of approximately $50,000 \mathrm{ft}^{2}$. Several architectural features are being implemented in the hospital to minimize power consumption. For example, clerestory will be used for indirect lighting and augmenting artificial lighting. High efficiency light sources such as compact fluorescents and high brightness LEDs will be used to minimize the power consumed by lighting. Partially sunken rooms are being planned for rooms that require air conditioning; e.g. labs. By utilizing the natural insulting value of the earth, the associated heating, ventilation and air-conditioning (HVAC) requirements of these rooms are minimized. Fortunately, even though Dodoma is located near the equator, the altitude of the DCMC is sufficient so that the annual average temperature is only on the order of $24^{\circ} \mathrm{C}$ which additionally eases HVAC requirements. The physical orientation of the hospital has been selected to maximize roof exposure for subsequent retrofitting with solar-photovoltaics should solar-photovoltaic costs fall enough to make this power option feasible. Roof overhang has also been designed to minimize direct exposure of rooms to sunlight. In order to minimize thermal loading all windows will be antireflection coated to reject infrared heat.

An extensive literature study was undertaken to determine the nominal power requirements for a hospital with the previously noted characteristics. It was quickly determined that there is very little public-domain data to aid in such an analysis. The major source of public-domain power data came from diesel genset (diesel engine driven generator) manufactures such as Cummins ${ }^{13}$. As an alternative, several hospitals ${ }^{14,15}$ and firms ${ }^{16,17,18}$ were directly contacted in an effort to help establish power guidelines. This approach proved to be very successful given the humanitarian nature of the DCMC project. Comparable hospitals that were used to help establish a power-baseline for the DCMC hospital are summarized in Table 1. 
Table 1. Power Statistics Normalized to 80 Beds for the DCMC Hospital

\begin{tabular}{|c|c|c|c|c|}
\hline Country & Hospital & Beds & $\begin{array}{l}\text { Pow er } \\
(\mathrm{kVA})\end{array}$ & $\begin{array}{c}\text { s0 Bed } \\
\text { Normalized } \\
\text { Power (kVA) }\end{array}$ \\
\hline \multirow[t]{2}{*}{ USA } & Mayo Clinic ${ }^{14}$ & Many & _-_ Note & --- Note \\
\hline & St Gabriel's ${ }^{15}$ & Many & _-_ Note & --- Note \\
\hline \multirow[t]{2}{*}{ Tanzania } & Selian Lutheran Hospital & 120 & $\sim 400$ & 267 \\
\hline & Chimal a Mission Hospital & 130 & $\sim 500$ & 307 \\
\hline \multirow[t]{5}{*}{ Malaysia } & Lahad Datu Hospital & 268 & 936 & 279 \\
\hline & Kuala Penya Hospital & 76 & 350 & 368 \\
\hline & Pitas Hospital & 76 & 350 & 368 \\
\hline & Kunak Hospital & 76 & 350 & 368 \\
\hline & Keningau Hospital & 212 & 800 & 302 \\
\hline Norway & Asker \& Baerum Hospital & 250 & 891 & 285 \\
\hline
\end{tabular}

Table 1 note: Due to mission and location differences, the power statistics for the Mayo Clinic and St. Gabriel's hospital were not used in the normalized power estim ates. However, both institutions provided significant support for assessing the data from hospitals similar to the DCMC hospital. The Selian and Chim ala power data is estim ated from private communications.

A detailed equipment list along with the associated power requirements is typically not known beforehand when designing a hospital. This is a reality of the constant evolution of medical equipment and the dynamic nature of medicine. Consequently 'rule-of-thumb' average powerdensity (Watt $/ \mathrm{m}^{2}$ or Watt $/ \mathrm{ft}^{2}$ ) constants for the various types-of-space are used to estimate overall power needs. Based on a significant amount of discussion, background assumption analysis, and the integrated experience set of the referenced experts, a reasonable set of power density constants were derived and are summarized in Table 2.

Table 2. Hospital Power Density Data.

$\begin{array}{cccc}\text { Area Type } & \begin{array}{c}\text { Power Density } \\ \left(\text { Watt } / \mathrm{ft}^{2}\right)\end{array} & \begin{array}{c}\text { Area } \\ \left(\mathbf{k f t} \mathbf{2}^{\mathbf{2}}\right.\end{array} & \begin{array}{c}\text { Power } \\ (\mathbf{k W a t t})\end{array} \\ \text { Critical }^{\text {Note 1 }} & 10 & 11 & 110 \\ \text { All Other }^{\text {Note 2 }} & 6 & 39 & 234 \\ \text { Total } & & 50 & 344\end{array}$

(1) 'Critical' areas include operating rooms, emergency rooms, imaging and analysis labs, and so forth

(2) 'All Other' areas include power for patient rooms, lighting, HVAC, medical and business support 
The total estimated power for the DCMC hospital appears reasonable when compared to the data presented in Table 1. Allowing for a $25 \%$ power margin, which includes peak-power and future expansion needs, the total estimated power that must be supplied for the DCMC hospital to operate is approximately $440 \mathrm{~kW}$. Several additional resources that were helpful when planning for the power needs of a hospital are noted in the references ${ }^{19,20}$.

TANESCO is responsible for supplying electrical power in Tanzania. Almost all of the electrical power supplied by TANESCO comes from hydroelectric plants located in northern Tanzania. Water for the hydroelectric facilities is captured during the rainy season which usually runs from November to March. During the rainy season and for much of the dry season, electricity is available in the major cities. However, the power grid is not reliable enough in the Dodoma region to run a modern hospital. During the rainy season, random power outages ranging from minutes to hours are common each week. Late in the dry season, and depending on national usage and management, power can be unavailable for days. Hence the on-site power systems for the DCMC hospital cannot be considered as 'low duty-cycle' backups but rather must be designed to handle the entire power needs of the hospital for extended periods of time (e.g. several days) in an 'island' mode-of-operation.

\section{Power and Infrastructure}

Today, taking into consideration the wide range of alternative-energy options, diesel gensets are still the dominant and most economical source of primary electrical power for almost all significant isolated power applications. In addition, diesel gensets form the backbone of most hospital power backup systems. Unfortunately, the present cost of diesel fuel in Tanzania is on the order of $\$ 5 /$ gallon and this price is expected to increase significantly in the coming years. In keeping with the desire to maintain and sustain the DCMC, any form of renewable energy that could supply the needs of the hospital and offset the price of diesel fuel would be very advantageous. As part of the service-learning work associated with this project, five undergraduate students spent 15 months evaluating the sustainable-energy-options generally available in Tanzania and specifically applicable for powering the DCMC. Four of the students were studying engineering (2 Mechanical Engineering students and 2 Electrical Engineering students) and the fifth was studying business. During the 15 month study, which began in September 2006, several alternative-energy sources were investigated, assessed and evaluated for powering the DCMC hospital ${ }^{21}$. The results for the more common alternative-energy options applicable to the DCMC are summarized in table 3. 
Table 3. Sustainable Energy Sources. (Straight Vegetable Oil $=$ SVO)

\begin{tabular}{|c|c|c|c|c|}
\hline Energy Source & $\begin{array}{l}\text { Viable In } \\
\text { Tanzania }\end{array}$ & $\begin{array}{l}\text { Viable In } \\
\text { Dodoma }\end{array}$ & $\begin{array}{c}\text { Capable of Meeting } \\
\text { Hospital Power } \\
\text { Requirements } \\
(440 \mathrm{~kW})\end{array}$ & $\begin{array}{c}\text { Economically } \\
\text { Viable } \\
\text { for the DCMC }\end{array}$ \\
\hline Solar PV & Yes & Yes & Yes & No \\
\hline Helios & Yes & Yes & Yes & No \\
\hline Wind & Yes & Yes & Yes & Yes \\
\hline Hydro & Yes & No & Yes & Not Available \\
\hline Geothermal & Yes & No & Yes & No \\
\hline Fuel Cells & Yes & No & Yes & No \\
\hline \multicolumn{5}{|l|}{ Bio fuels: } \\
\hline Biodiesel & Yes & No & Yes & No \\
\hline SVO & Yes & Yes & Yes & Maybe \\
\hline Algae SVO & No & No & Yes & No \\
\hline
\end{tabular}

The results of this study were revealing. By prime-mover power standards, the $440 \mathrm{~kW}$ needed to run the DCMC hospital is a moderate-to-small power quantity at best. Yet other than burning diesel fuel, wind power is the only economical source of sustainable energy capable of meeting the hospital power needs. Under protection from a non-disclosure agreement (NDA), the wind potential of the DCMC site and that of Tanzania in general was analyzed for the DTHD by WindLogics ${ }^{22}$. An example of the wind data for the DTHD site is illustrated in figure 4. Figure 4a is a topographical map of the site where GPS readings were used to pinpoint possible sites (bold dots) for wind turbines and to correlate actual site data with satellite imagery. The hills surrounding the site are on average on the order of 150 meters above the surrounding planes. Annual average wind-speeds for the site are illustrated in figure $4 \mathrm{~b}$. The red regions in figure $4 \mathrm{~b}$ indicate average wind speeds on the order of $8 \mathrm{~m} / \mathrm{s}$ which are sufficient for power production. Summarizing, Tanzania has considerable wind power potential. 


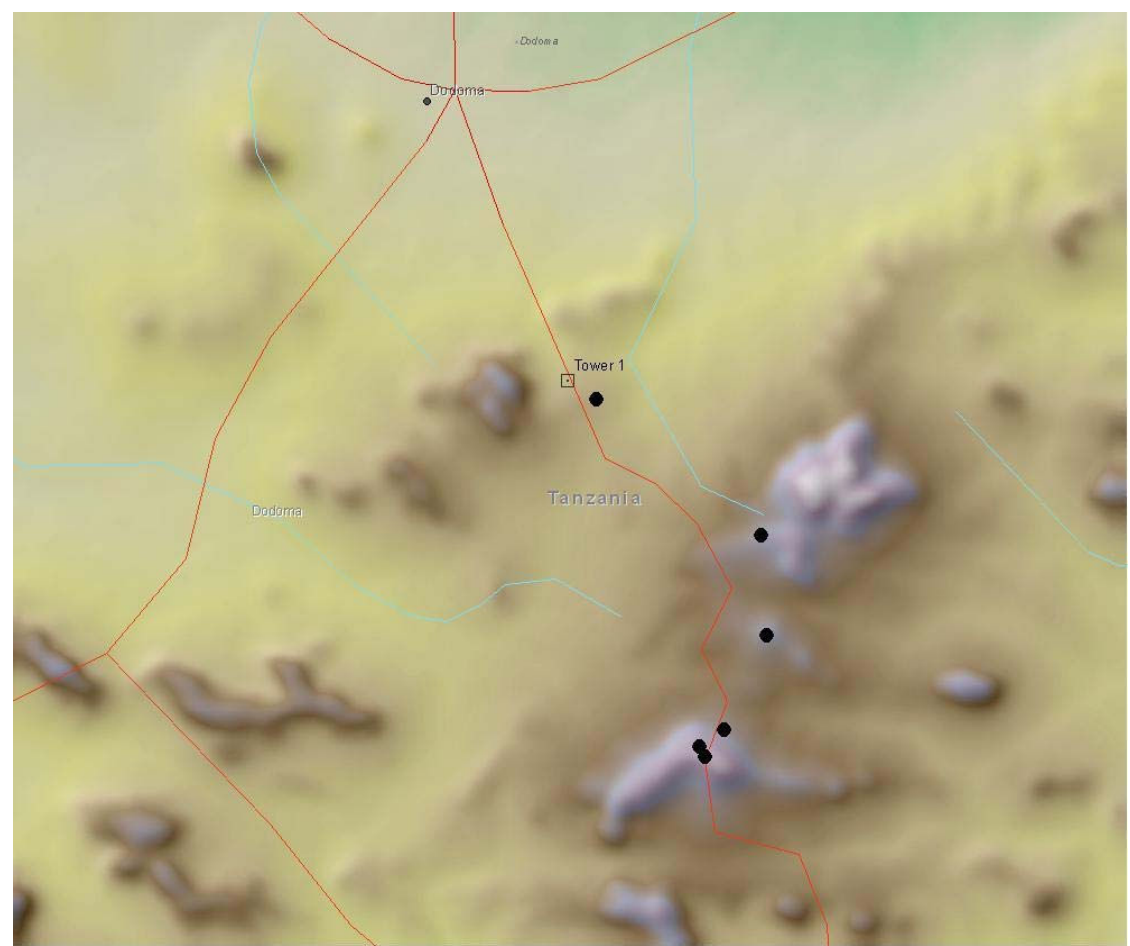

(a)

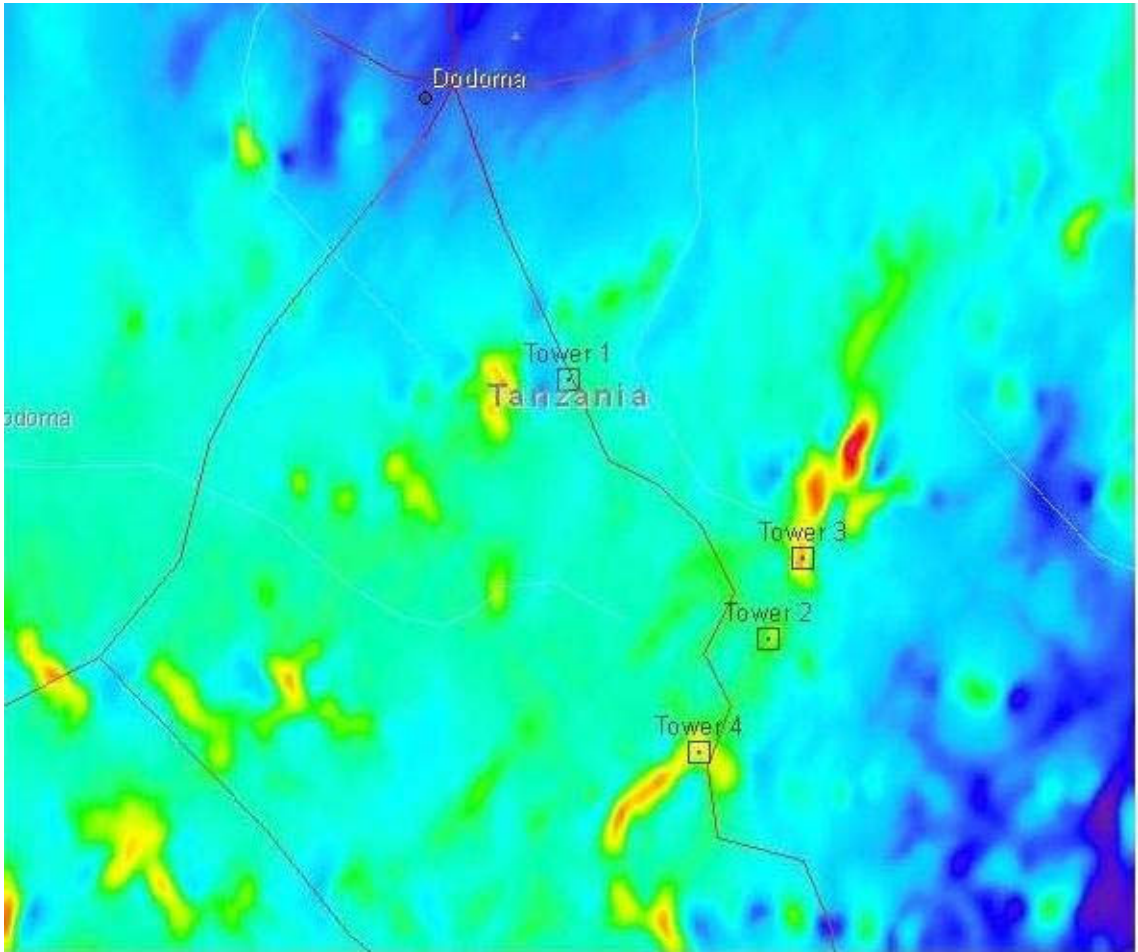

(b)

Figure 4. (a) Topographical map of DTHD site. (b) Annual average wind-speed map of site. $(1 \mathrm{~cm}=500$ meters $)$ 
The cost of a solar photovoltaic system capable of supplying the hospital power requirements was on the order of ten-to-fifteen times that of wind power while the cost of a fuel-cell (any type) based power system was on the order of twenty times that of wind power. Aside from efficiency, availability and technology costs, another aspect of the economic issues associated with solar photovoltaic and fuel cells stems from the fact that both are DC power sources. Since most equipment requires $\mathrm{AC}$ power, some form of power-storage, power management and $\mathrm{DC}-\mathrm{AC}$ conversion must also be considered with these energy sources which adds to the overall system costs and complexity.

Biofuels were also considered as a source of power in this study. The primary goal of this portion of the study was to evaluate powering diesel gensets with alternatives to petrel-diesel fuel; such as straight vegetable oil (SVO). While several stock-sources of SVO for producing biodiesel are known, such as restaurant grease, oil producing crops or algae, they are not economically viable in Tanzania. Modern diesel engines are very capable of using SVO. Indeed, this was the fuel of choice for the original diesel engine. Several manufactures produce diesel gensets that are warranted for use with $\mathrm{SVO}^{23,24}$. However, the only method of obtaining an economically viable source of SVO in Tanzania is via agricultural methods. It is also undesirable to use oil producing crops which are also food sources as this tends to drive up the cost of food and in developing countries and can lead to disastrous consequences ${ }^{25}$. Non food-source SVO crops such as jatropha grow well in Tanzania but the time-frame for implementing this option was unacceptable for this project. This option is being considered as a 'phase-2' follow-on once the hospital is completed.

The implications of this power study, from a global power perspective, are also very troubling. It appears that the only economical and viable method of generating large amounts of power, other than hydro and wind, is to burn a fuel (e.g. coal, oil or nuclear). Given the present worldwide energy needs, the projected world-wide growth for electrical power and the diminishing availability of natural resources such as oil, this does not bode well for the future. Much work remains to be done in the arena of power generation and distribution.

The investigation and planning process for identifying sustainable methods of powering the DCMC hospital was only the first step, of many, toward ultimately installing the hospital power systems. The engineering challenges for implementing a power system in a developing country are significant. For illustrative purposes, let's assume for the moment that wind-power will be used as a means of powering the hospital as well as providing a source of sustainable income by selling power to TANESCO. A typical 2-MW, 3-blade, grid-capable wind turbine (WT) is a mammoth structure. The nacelle of this WT (whose size approximates that of the trailer of a tractor-trailer truck) typically rests upon a 100 meter high tube-tower and weighs about 40 tons. Each blade of the WT is on the order of 40-meters long and weighs approximately 1.5 tons. The WT base used to anchor the tube-tower is typically a buried cube of reinforced concrete with each side measuring approximately 15 meters. In developed countries, the civil engineering infrastructure routinely supports the construction of these types of grid-capable WTs. Much to our surprise, our research revealed that there are no cranes in Africa capable of lifting and assembled a standard 2-MW wind turbine. Even if the required cranes could be found in Africa, the roads in Tanzania are generally too narrow and of insufficient strength to support 
transportation of the crane and WT nacelle from the costal shipping ports to the actual site. Hence tube-towers cannot be readily used for WTs in Tanzania. Furthermore, the geology of the hills surrounding the DCMC is not compatible with a buried cube base. Also, the blades of a 2megawtt WT do not fit in a standard $10-\mathrm{ft}$ by 10 -ft by 40 - $\mathrm{ft}$ shipping container. Hence shipping a WT from the manufacturer to the site also constitutes a major engineering and logistics problem.

Smaller WTs were also considered in this study and are feasible. However, due to WT power scaling as a function of size (i.e. bigger WTs generate more power than smaller WTs) the ability to generate enough power to meet the hospital requirements and sell power to TANESCO is compromised. Using an array of smaller WTs will be reserved as an alternative option depending on factors discussed in the status section.

Several engineering innovations were developed by the author and the students to address the problems associated with installing grid-capable WTs in Tanzania. The non-standard shipping problems were overcome by working closely with the potential WT manufacturers and leveraging their experiences in the world-wide transportation and assembly of WTs. For example, a standard practice is to complete the nacelle at the WT manufacturing site and then ship the completed nacelle to the intended location. In cooperation with the WT manufacturer the nacelle will be assembled at our site. This minimizes the shipping weight of each nacelle subsystem which in turn eases the load-bearing requirements on the roads and bridges in a developing country. Lattice towers will be used to support the WTs instead of tube towers since lattice towers do not require a massive subterranean base of reinforced concrete. It is often very difficult to obtain the proper materials for a WT cube-base and even more difficult to excavate the often remote site in developing countries. A new method of erecting WTs, the 'Plus-1' method ${ }^{26}$, was invented by the author and the students. This method does not require the use of the cranes commonly employed in erecting traditional grid-size WTs. Training native Tanzanian technicians to maintain the WTs is being done in cooperation with the WT manufacturers and the University of Dar es Salaam.

\section{Status}

The general features and architectural details of the DCMC hospital have been completed. The power systems for the hospital have been defined and three business units are now generating revenue. Multiple financial agreements are in the process of being negotiated. Hospital construction will commence once the financial agreements have been finalized. The hope is that the construction of the hospital and power systems will commence sometime during 2008 .

\section{Summary and Conclusion}

The business model previously described in this paper is being successfully used. Three local business units are now operating and generating a net income - which is essential for ultimately sustaining the hospital. This success represents an important first step. The business model is general enough so that it can be readily modified to address a wide variety of circumstances and can serve as a template for similar projects in other developing countries. The business model is based on providing medical services (or some other service) to the local population and 
producing a sustainable source of income via power generation and providing for local businesses and entrepreneurship. Solutions to several of the engineering challenges associated with implementing grid-level wind-power in Tanzania have been invented. The project has proven to be very fertile for engaging students in service-learning opportunities. The hospital and associated power systems are expected to come on-line in the $2010-2011$ timeframe.

\section{Acknowledgements}

This is a large project and as such its success rests upon the contributions from many individuals. First of all, it is important to acknowledge the DTHD Board of Trustees for their maintainable and sustainable vision in this undertaking for without vision, nothing substantive is possible. The author would also like to acknowledge the generous support of many individuals in the power industry whom helped educate the author in the details of providing primary and backup power for a hospital. This includes Tom DeBoer from the Mayo Clinic Franklin Heating Station, Lynden Johnson and Kevin O'Neil with St. Gabriel's Hospital in Little Falls, Minnesota, Bob Bayne and Robert Cain of Grumman/Butkus Associates, Jeff Hankin of Sparling and Bruce Levy of TDX Power. Without their help and support the power aspects of this project would have been severely handicapped. Finally, I would like to thank the students who dedicated 15 months of effort toward helping the author research, plan and begin implementing the power elements of this project; in particular, Andrew DePompolo, Steve Lay, Andre Trawick, Katherine Kaspar and Kevin Maas. There diligence, spirit and commitment has been inspiring and wonderful.

\section{Bibliography}

1. The Dodoma Tanzania Health development (DTHD), www.dthd.org.

2. www.stthomas.edu/engineering/outreach/servicelearning/default.html.

3. "Global Energy Futures and Human development: A Framework for Analysis", A. D. Pasternak, U.S. Department of Energy, October 2000.

4. www.usaid.gov.

5. "Too much of a Good Thing: Choking on Aid Money in Africa", Der Speigel 27/2005 - July 4, 2005, by Erich Wiedermann and Thilo Thielke.

6. Author's note: the identified organizations were selected for illustrative purposes only with nothing else implied or meant to be implied in any way.

7. www.ChristianChildrensFund.org.

8. www.ewb-usa.org/.

9. www.peacehousefoundation.org.

10. www.dthd.org/new.htm; Photos of the presidential event as well as overall site photos can be viewed at this web site.

11. Small Tanzanian wind turbine entrepreneur.

12. www.tanesco.com.

13. www.cumminspower.com.

14. Mayo Clinic, Franklin Heating Station, 119 Third Street SW, Rochester, MN 55902; www.mayoclinic.com. Tom DeBoer - Chief Power Engineer (CPE).

15. United family Healthcare - St. Gabriel's Hospital, 815 S.E. $2^{\text {nd }}$ Street, Little Falls, MN 56345. Lynden Johnson - CPA, Kevin O'Neil - Director of Facilities services.

16. Grumman/Butkus Associates, 1011N. Mayfair road, suite 300, Wauwatosa, WI, 53226. www.grummanbutkus.com. Bob Bayne - President and Robert Cain - Project Manager Electrical. 
17. Sparling, 720 Olive Way, Suite 1400, Seattle, Washington 98101-1853. www.sparling.com. Jeffery S. Hankin, PE, LEED - Principal.

18. TDX Power Inc., 4300 B Street, Suite 402, Anchorage, AK 99503. www.tdxpower.com. Bruce Levy President.

19. "IEEE Recommended Practice for Electrical Systems in Health Care Facilities", IEEE Std 602-1996.

20. NFPA 70: National Electric Code ${ }^{\mathbb{B}}$ International Electric $\operatorname{Code}^{\mathbb{}} 2005$.

21. "Sustainable Energy Options in Tanzania"; to be published. The primary authors of this paper are the five students noted in the acknowledgements.

22. WindLogics; www.windlogics.com.

23. www.manbw.com.

24. www.wartsila.com.

25. "Sustainable Bioenergy: A framework for Decision Makers", United Nations, http://esa.un.org/unenergy/pdf/susdev.Biofuels.FAO.pdf.

26. The 'Plus-1' method of erecting wind turbines is in the 'patent pending' stages along with a 'to be published' technical description of the details. 